\title{
EATING HABITS AND DIETARY INTAKE: IS ADHERENCE TO DIETARY GUIDELINES ASSOCIATED WITH IMPORTANCE OF HEALTHY EATING AMONG UNDERGRADUATE UNIVERSITY STUDENTS IN FINLAND?
}

\author{
Walid El Ansari', Sakari Suominen ${ }^{2,3,4}$, Anastasia Samara ${ }^{5}$ \\ ${ }^{1}$ Faculty of Applied Sciences, University of Gloucestershire, Gloucester, United Kingdom \\ 2Department of Public Health, University of Turku, Turku, Finland \\ ${ }^{3}$ Nordic School of Public Health, Gothenburg, Sweden \\ ${ }^{4}$ Folkhälsan Research Centre, Helsinki, Finland \\ ${ }^{5}$ Unit for Health Promotion Research, Institute of Public Health, University of Southern Denmark, Esbjerg, Denmark
}

\section{SUMMARY}

Aim: Poor eating habits among young adults are a public health concern. This survey examined the eating habits of undergraduate university students in Finland. We assessed students' dietary intake of a variety of food groups, their adherence to international dietary guidelines (whole sample and by gender), and the associations between importance of eating healthy and dietary guidelines adherence (whole sample and by gender).

Methods: During the 2013-2014 academic year, 1,189 undergraduate students enrolled at the University of Turku in southwestern Finland completed an online self-administered questionnaire. Students reported their eating habits of 12 food groups, the number of daily servings of fruits/ vegetables they consume and how important it is for them to eat healthy. For dietary adherence recommendations, we employed WHO guidelines. Chi-square statistic tested the differences in dietary guidelines adherence between males and females and also the associations between the gradients of importance of healthy eating and the self reported eating habits for each of the food groups, for the whole sample and by gender.

Results: We observed high levels of dietary adherence ( $>70 \%$ ) for most of the 'unhealthy food' items (cake/cookies, snacks, fast food/canned food, and lemonade/soft drinks), and moderate adherence for most of the 'healthy food' items $(>50 \%$ ) (dairy/dairy products, fruit/vegetables servings/day, fresh fruit, salads/raw vegetables and cereal/cereal products). Fish/seafood, meat/sausage products and cooked vegetables had levels $<50 \%$ for adherence to the guidelines. Women had better adherence for meat/sausage products, fast food/canned food and for most 'healthy food' items ( $p \leq 0.001$ ), whereas men had better adherence for sweets (difference $=12.8 \%, p \leq 0.001$ ), lemonade/soft drinks (difference $=16.7 \%$, $p \leq 0.001$ ) and fish/seafood (difference $=6.6 \%, p=0.040$ ) compared to women. Most students considered important to eat healthy $(78.8 \%)$. The importance of eating healthy was significantly associated with adherence for all food groups besides sweets and cake/cookies. These associations remained significant for women but some of them not for men (cereal/cereal products, snacks and sweets).

Conclusions: The results suggest high adherence to the guidelines mainly for 'unhealthy food' groups, and moderate adherence for healthier food groups. There was also accordance between regarding eating healthy as important and actually eating healthy. However, there are improvements to be considered for specific food groups, as well as gender differences when implementing public health strategies related to food intake.

Key words: Finland, food intake, gender, students' health, eating healthy, dietary guidelines adherence

Address for correspondence: W. El Ansari, Faculty of Applied Sciences, University of Gloucestershire, Oxstalls Campus, Oxstalls Lane, Gloucester GL2 9HW, United Kingdom. E-mail: walidansari@glos.ac.uk

\section{INTRODUCTION}

With the transition from secondary school to university, as independency increases, students are constantly challenged to make healthy food selections (1). Such transition into young adulthood is frequently a period of unhealthy lifestyle where young people could assume long-lasting health behaviour habits $(2,3)$. In particular, college students are exposed to unhealthy eating habits leading to body weight gain, and make their independent food choices, sometimes based on cost of food and availability of fast food (4).
University populations are vulnerable in their eating habits for various reasons. Students might be deficient in their knowledge of healthy food selections that could negatively influence their eating habits (4). Financial aspects might also play a role, as fats and sweets cost less, whereas many healthier foods cost more (5), and increased financial concerns are associated with worse health (6). Students also face academic responsibilities that may generate stress and lead to changes in eating habits (7). In addition, students'eating behaviour could be affected by university characteristics, e.g. student societies, university lifestyle and exams (1), and by the college nutrition environment and its contribution 
to adoption of healthy/unhealthy eating habits (8). Students can buy food during lecture breaks and usually eat at the university refectory where fruits might not be readily available and food choices are limited (9). Students' accommodation/changes in living arrangements that some students encounter also influence their food choices where dietary intakes might feature unfavourable practices, especially for those not living with parents or those who move to another county or country to attend university (10). For instance, Greek students faced difficulties in maintaining a traditional Mediterranean diet after leaving the family home and moving to Northern Europe (10), and the same was reported for Portuguese university students (11). Nonetheless, universities provide appropriate opportunities/environment to reach many young adults through nutrition education efforts to positively influence their dietary intakes and encourage them to embrace healthy food choices.

The food consumption habits and dietary intakes of university students across the globe seem to be characterized by unhealthy choices. In Saudi Arabia, only $17.2 \%$ of the female university students surveyed consumed fruit and vegetable daily (2), and likewise, among female nursing students, only $30 \%$ ate fruit and vegetable daily (12). In Spain, a low percentage of undergraduate students adhered to the new Nutritional Pyramid of the Spanish Nutrition Society recommendations for pasta, bread and cereals, vegetables, fruits, and legumes (13), and among a university population $75.5 \%$ of future teachers needed improved adherence to the Mediterranean diet (14). Likewise, $90 \%$ of Galician university students needed to modify their eating habits to conform to a heart-healthy diet (15), and in Poland, calcium intakes of female students were inadequately low (16). In agreement, in Malaysia, university students had unhealthy eating behaviour and inadequate nutrient intakes (4), and in Chile, university students had low/ average adherence to the Mediterranean diet (17). Indeed, in the USA, $>30 \%$ of college students were overweight or obese despite evidence that uphold the association between diet features and health either as risk factors or as providers of beneficial/protective effects in relation to a range of chronic conditions (18).

Nutritional knowledge alone seems useful but not sufficient for appropriate dietary adherence. On the one hand, adherence to dietary recommendations among Croatian university students was significantly associated with nutrition knowledge scores (19). In contrast, in Hong Kong, whilst most university students knew that fruits are part of a healthy diet, $>60 \%$ failed to eat fruit daily (9). Similarly, Greek nutrition students had average adherence to the Mediterranean diet (20), and Polish human nutrition students had low calcium intakes despite having sufficient knowledge through studying this subject area (16). Given such findings, in the current study we additionally assessed students' subjective perception of the importance of healthy eating and its relationship to dietary guidelines adherence.

Little eating habits/dietary intake research has been undertaken in Finland, particularly among university students and especially across a wide range of food groups. Some Finnish studies of eating habits/diet were either population based (21), conducted among adolescents (22) or elementary school children (23), while others examined the consumption of isolated food groups, e.g. daily vegetable or bread consumption $(21,24)$. Interestingly, among university populations in Finland, some risk factors of non communicable chronic diseases have received more attention: whilst there exist studies on smoking, drinking and physical exercise $(25,26)$, there is little research on dietary intake/dietary guidelines adherence of these young adults. For instance, since 2000 a national university student health survey has been carried out only four times in Finland (27), and there is a dearth of government or country report/s of the nutritional quality of university students.

Therefore, the current study examined the eating habits and dietary intake of a sample of students at the University of Turku and assessed, for the whole sample and by gender, students' intake of a range of food groups in terms of the extent of their adherence to recommended international dietary guidelines. In addition, we focused on the question: "Is adherence to dietary guideline associated with the subjective importance of healthy eating among undergraduate university students in Finland?" Enriching the knowledge base is essential to inform future educational, prevention and intervention efforts for these young adults. Thus, the current study bridges these knowledge gaps and these features assign high significance to the contributions and findings of the current research.

\section{MATERIALS AND METHODS}

The study was a general student health and wellbeing survey similar to studies of student health implemented in several countries (28). It included self-reported socio-demographic and anthropometric information (e.g., gender, age, weight, height), questions on the consumption habits of a range of food groups, an item on the importance of eating healthy, as well as university study related questions. Mean age and BMI were $23( \pm 5)$ years and $22.7(3.6) \mathrm{kg} / \mathrm{m}^{2}$ (age range 18-65 years, BMI range $16-60 \mathrm{~kg} / \mathrm{m}^{2}$ ).

\section{Sample, Ethics, Procedures and Data Collection}

The research and ethics committee at the university approved the study (identification number Lausunto 10/2010), and data were collected via a secure online survey during the academic year 2013-2014 at the University of Turku in Turku, Finland. The study tool was an online self-administered questionnaire in English language. An initial invitation email was sent to all first, second and third year undergraduate students at all faculties at the University outlining the aims and objectives of the research and inviting them to participate in the study by completing the online survey. Participation was voluntary and anonymous with no incentives provided and data were confidential and protected. Students were also provided with contact information in case they had questions or wished to discuss any aspect of the study, and were informed that by completing the online survey they agree to participate in the study. As a follow up, two weeks after the first email invitation to the students, a reminder invitation email was sent again to all first, second and third year undergraduate students. In addition, three posters about the study were placed in the students' cafeteria/refectory at the University at various locations. An initial pilot survey was conducted in May 2013 to a randomly assigned sample (200 students) stratified according to faculties. Only very few respondents reported any comprehensibility problems related to the questionnaire being in English, and the number of missing values related to items that reasonably could be expected to be answered by all was negligible. Thus the 
actual survey was then commenced with the unchanged questionnaire in September 2013. The pilot sample was excluded from the final eligible sample which comprised 4,387 students at the University of Turku.

As students completed the online survey by clicking the 'submit' button, their electronic responses were automatically saved and sent to the Student Management Office at the University of Turku. The Student Management Office collated the completed online responses, and the data were electronically entered into an excel sheet ensuring a high quality assurance. Only after this stage was completed, the data was then sent to the research team who then electronically imported the data (without any identifiers) into the SAS software for the analysis. The total number of responses received was 1,189 . After excluding questionnaires that had missing values for the variables under examination 1,104 participants remained in the dataset (323 males, 781 females) and were used for the current analysis. Participating students were enrolled at all seven faculties of the University of Turku (Faculties of Humanities, Mathematics and Natural Sciences, Medicine, Law, Social Sciences, and Economics). Based on the number of returned questionnaires, the response rates were about $\approx 27 \%$.

\section{Health and Wellbeing Questionnaire}

Assessment of food consumption habits (12 items). Students self-reported their nutritional habits in a food frequency questionnaire comprising 12 indicator variables that measured their consumption of sweets, cakes/cookies, snacks and fast/canned food, fresh fruits, raw and cooked vegetables and salads, meat and fish, milk products, and cereals. The introductory question "How often do you eat the following foods?" queried students about the frequency of their usual consumption of each food group individually (5-point scale: 'several times a day', 'daily', 'several times a week', '1-4 times a month', and 'never'). In agreement with others, the instrument incorporated food groups that are important for dietary habits research, and the face and content validity of the tool were established by grounding the questionnaire on wide literature review. The instrument was based on pre-existing food frequency questionnaires adapted for the study and used in previous publications (28). We did not conduct a formal test of validity, but the questionnaire was very analogous to other validated food frequency questionnaires $(29,30)$.

Number of servings of fruits/vegetables consumed per day (1 item). "How many servings of fruits and vegetables do you usually have per day ( 1 serving $=1$ medium piece of fruit, $1 / 2$ cup chopped, cooked or canned fruits/vegetables, 3/4 cup fruit/vegetable juice, small bowl of salad greens, or $1 / 2$ cup dried fruit)?" The response scales were: 'I don't eat fruits and vegetables', '1-2 times', '3-4 times', or '5 or more times'.

Importance of eating healthy (1 item). "How important is for you to eat healthy?" on a 5 -point scale ( 1 = 'not at all important' to $5=$ 'very important'). Due to small counts for the categories $1,2,3$, the five categories were later collapsed into two broader categories: 1, 2, 3 ('not important') and 4, 5 ('important') for the analysis.

Ease of completion of the questionnaire in English language (1 item). The online questionnaire was in English language and was not translated into Finnish as the great majority of students were proficient in English. Hence the questionnaire included a question on the ease of completion of the questionnaire in English language for Finnish students: "Responding to a questionnaire in English was for me", with 5 response options ('easy', 'rather easy', 'not as easy as if the questionnaire had been in my mother tongue', 'somewhat difficult', 'very difficult').

As for the dietary guidelines, for the items sweets, cake/ cookies, snacks, fast food/canned food and lemonade/soft drinks no specific guidelines exist; hence, we employed ' $1-4$ times a month' and 'never' as recommended. For all the remaining food groups, we used the WHO dietary guidelines recommendations (31). Consequently, for the number of daily fruit/vegetables servings, ' $3-4$ times' and ' $\geq 5$ times' were considered as recommended because the international guidelines suggest 5 servings of vegetables/day and 4 servings of fruit/day (31). In terms of the fresh fruit, salad/raw vegetables, cooked vegetables, dairy/dairy products, and cereal/cereal products, we considered the 'several times a day' and 'daily' categories as recommended (31). For the meat/sausage products, the recommendations are 1-2 servings/ week (31), therefore we considered as recommended, people who consumed these items ' $1-4$ times a month' and 'never'. Finally, as regards to eating fish/seafood, the guidelines suggest at least 2 servings/week (31), so we considered as recommended, people who consumed these items 'several times a day', 'daily' or 'several times a week' (31).

\section{Statistical Analysis}

We employed the SAS software package v9.3(SAS institute, Cary, NC) for the statistical analyses (statistical significance set at $\mathrm{p} \leq 0.05$ ). Descriptive statistics (frequencies) described students' diet quality and food consumption patterns, as well as the percentages of students who adhered to international dietary guidelines (for the whole sample and also separately for men and women).

Chi-square statistic was used to test the overall differences for adherence to the dietary guidelines between male and female students, and also the associations between the importance of healthy eating and the actual self reported food consumption habits for all food items, for the whole sample and for males and females separately. If cell counts were $<5$, Fisher's exact test was used. Adjustments were undertaken for age and BMI for all chi-square analyses.

\section{RESULTS}

\section{Ease of completion of the questionnaire in English language}

Most participants indicated that responding to the online questionnaire in English language was either 'easy' $(n=244,21 \%)$, 'rather easy' $(n=644,55 \%)$, or 'not as easy as if the questionnaire had been in my mother tongue' ( $n=216,19 \%)$, with only a minority of students reporting that it was 'somewhat difficult' $(n=63,5 \%)$ or 'very difficult' $(n=3,0 \%)$.

\section{Eating Habits of University Students in Finland}

Table 1 depicts students' eating habits (frequencies) for 12 food items for the whole sample $(\mathrm{N}=1,111)$. Cake/cookies, 
snacks and fast food/canned food had very similar distributions, whereas sweets and lemonade/soft drinks had more distinct distributions. All these food groups had very low percentages of consumption for the 'several times per day' or 'daily' categories. Only sweets had high percentages of intake for 'several times a week' (41.5\%), whereas lemonade/soft drinks had the highest levels $(21.7 \%)$ of 'never' being consumed compared to all the other above mentioned food groups. Fresh fruits and raw vegetables had also similar distributions, with very low percentages of 'never' being consumed. Cooked vegetables were more often consumed 'several times a week' compared to fresh fruit and raw vegetables which were more often consumed on a 'daily' and 'several times per day' basis. Meat and fish intake differed in their distribution, with meat consumed often 'daily' or 'several times a week', and fish mostly consumed 'several times a week' and ' $1-4$ times a month'. Dairy products were mostly consumed 'several times a day' or 'daily', whereas cereal/cereal products had a high 'daily' consumption. In addition, dairy products had the highest consumption for 'several times per day' compared to all other food groups (40.1\%).

\section{Adherence to Dietary Guidelines: Whole Sample and by Gender}

Table 2 describes the frequencies of adherence to dietary guidelines for the different food groups (12 items, and a question on number of daily servings of fruit/vegetables), for the whole sample $(\mathrm{N}=1,111)$, as well as for 323 male and 781 female students $(\mathrm{N}=1,104)$. Food items were grouped according to their similarities for dietary guidelines. For the whole sample, we observed high percentages of adherence to guidelines for cake/ cookies $(84.8 \%$ ), snacks $(87.9 \%)$, fast food/canned food $(89.0 \%)$, lemonade/soft drinks (77.5\%) and dairy/dairy products $(77.2 \%)$. Sweets, fruit/vegetables servings/day, fresh fruit, salads/raw vegetables and cereal/cereal products also had relatively high percentages of guidelines adherence but not cooked vegetables (28.6\%). Meat/sausage products and fish/seafood intake exhibited low levels of compliance with the guidelines, with meat/sausage products having lower adherence than fish/seafood and also the lowest adherence (23.6\%) compared to all the food groups studied.

When men and women were analyzed separately, there were differences in guidelines adherence across many food groups. The associations were adjusted for BMI and age. Men showed significantly higher levels of compliance for sweets and lemonade/ soft drinks, but lower adherence for fast food/canned food. No significant gender differences were observed for cake/cookies and snacks. For fruits and vegetables, women had significantly higher adherence for all of the food groups $(p \leq 0.001)$. Women had significantly higher levels of compliance with guidelines for meat/sausage products but not for fish/seafood. In addition, women had significantly higher guidelines adherence for cereal/ cereal products. There were no gender differences in adherence levels for dairy/dairy products.

\section{Is Adherence to Dietary Guidelines Associated with Importance of Healthy Eating for Whole Sample and by Gender?}

Table 3 shows the associations between eating habits and the importance of eating healthy for the whole sample $(\mathrm{N}=1,111)$, adjusted for BMI and age. Most students felt it is important to eat healthy $(78.8 \%)$. Across the sample, all food groups were strongly and significantly associated with the importance of eating healthy, with the exception of cake/cookies and sweets.

Table 4 illustrates the associations between eating habits and the importance of eating healthy by gender $(\mathrm{N}=1,104$ participants). The associations remained significant for both genders for many food groups (fruit/vegetable servings/day, salads/raw vegetables, fresh fruit, cooked vegetables, dairy/dairy products, fast food/canned food, lemonade/soft drinks, and fish/seafood). However, there were also gender differences, where cereal/cereal products, snacks, meat/sausage products and sweets remained statistically significant for women but not for men. All associations were adjusted for BMI and age.

Table 1. Eating habits of 12 food groups of undergraduate university students in Finland $(N=1,111)$

\begin{tabular}{|c|c|c|c|c|c|}
\hline & Several times per day & Daily & $\begin{array}{l}\text { Several times } \\
\text { per week }\end{array}$ & 1-4 times per month & Never \\
\hline & $n(\%)$ & $n(\%)$ & $\mathrm{n}(\%)$ & $n(\%)$ & $n(\%)$ \\
\hline Sweets $^{\mathrm{a}}$ & $4(0.4)$ & $68(6.1)$ & $461(41.5)$ & $531(47.8)$ & $47(4.2)$ \\
\hline Cake/cookies & $2(0.2)$ & $12(1.1)$ & $155(14.0)$ & $829(74.6)$ & $113(10.2)$ \\
\hline Snacks $^{b}$ & $0(0)$ & $5(0.5)$ & $130(11.7)$ & $833(75)$ & $143(12.9)$ \\
\hline Fast food/canned food ${ }^{c}$ & $0(0)$ & $5(0.5)$ & $117(10.5)$ & $870(78.3)$ & $119(10.7)$ \\
\hline Fresh fruit & $175(15.8)$ & $402(36.2)$ & $407(36.6)$ & $117(10.5)$ & $10(0.9)$ \\
\hline Salad/raw vegetables & $195(17.6)$ & $565(50.9)$ & $298(26.8)$ & $51(4.6)$ & $2(0.2)$ \\
\hline Cooked vegetables & $58(5.2)$ & $260(23.4)$ & $479(43.1)$ & $268(24.1)$ & $46(4.1)$ \\
\hline Lemonade/soft drinks & $8(0.7)$ & $33(3.0)$ & $209(18.8)$ & $620(55.8)$ & $241(21.7)$ \\
\hline Meat/sausage products & $58(5.2)$ & $352(31.7)$ & $439(39.5)$ & $139(12.5)$ & $123(11.1)$ \\
\hline Fish/seafood & $3(0.3)$ & $34(3.1)$ & $418(37.6)$ & $557(50.1)$ & $99(8.9)$ \\
\hline Dairy/dairy products & $446(40.1)$ & $412(37.1)$ & $167(15.0)$ & $57(5.1)$ & $29(2.6)$ \\
\hline Cereal/cereal products $^{d}$ & $180(16.2)$ & $430(38.7)$ & $283(25.5)$ & $144(13.9)$ & $74(6.7)$ \\
\hline
\end{tabular}

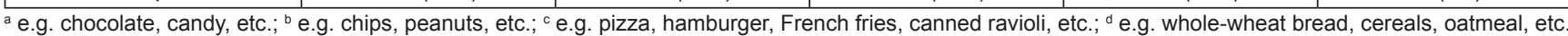


Table 2. Finnish students' adherence to dietary guidelines: whole sample and by gender

\begin{tabular}{|c|c|c|c|c|}
\hline & \multicolumn{4}{|c|}{ Adherence to guidelines } \\
\hline & $\begin{array}{l}\text { Whole sample } \\
\qquad N=1,111\end{array}$ & $\begin{array}{c}\text { Men } \\
\mathrm{N}=323\end{array}$ & $\begin{array}{l}\text { Women } \\
N=781\end{array}$ & \multirow[t]{2}{*}{$\mathrm{p}^{t+t}$} \\
\hline & $\mathrm{n}(\%)$ & $\mathrm{n}(\%)$ & $\mathrm{n}(\%)$ & \\
\hline Sweets ${ }^{\text {a }}$ & $578(52.0)$ & $198(61.3)$ & $379(48.5)$ & $\leq 0.001$ \\
\hline Cake/cookies $^{\dagger}$ & $942(84.8)$ & $284(87.9)$ & $653(83.6)$ & ns \\
\hline Snacks ${ }^{\text {b† }}$ & $976(87.9)$ & $274(84.8)$ & $696(89.1)$ & ns \\
\hline Fast food/canned food ${ }^{\text {c }}$ & $989(89.0)$ & $254(78.6)$ & $729(93.3)$ & $\leq 0.001$ \\
\hline Lemonade/soft drinks $^{\dagger}$ & $861(77.5)$ & $643(82.3)$ & $212(65.6)$ & $\leq 0.001$ \\
\hline Number of fruit/vegetables servings per day tt & $621(55.9)$ & $130(40.3)$ & $487(62.4)$ & $\leq 0.001$ \\
\hline Salad/raw vegetables* & $760(68.4)$ & $186(57.6)$ & $569(72.9)$ & $\leq 0.001$ \\
\hline Cooked vegetables* & $318(28.6)$ & $64(19.8)$ & $252(32.3)$ & $\leq 0.001$ \\
\hline Fresh fruit* & $577(51.9)$ & $115(35.6)$ & $458(58.6)$ & $\leq 0.001$ \\
\hline Dairy/dairy products* & $858(77.2)$ & $249(77.1)$ & $607(77.7)$ & ns \\
\hline Cereal/cereal products ${ }^{\mathrm{d} *}$ & $610(54.9)$ & $141(43.7)$ & $464(59.4)$ & $\leq 0.001$ \\
\hline Meat/sausage products** & $262(23.6)$ & $38(11.8)$ & $219(28.0)$ & $\leq 0.001$ \\
\hline Fish/seafood $d^{* * *}$ & $455(41.0)$ & $148(45.8)$ & $306(39.2)$ & 0.040 \\
\hline
\end{tabular}

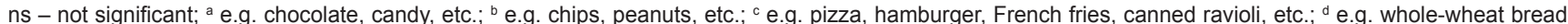
cereals, oatmeal, etc.; ${ }^{\dagger}$ No specific guidelines exist, 1-4 times/month or never considered as recommended; $+\dagger 3-4$ or $\geq 5$ servings considered as recommended; *several times a day/daily considered as recommended; ${ }^{* *} 1-4$ times/month or never considered as recommended; ${ }^{* * *}$ several times a day/daily/several times a week considered as recommended; ${ }^{+t} \mathrm{p}$ values adjusted for BMI and age

Table 3. Associations between importance of eating healthy and dietary guidelines adherence: whole sample $(N=1,111)$

\begin{tabular}{|c|c|c|c|}
\hline & \multicolumn{3}{|c|}{ Importance of eating healthy } \\
\hline & Not important & Important & \multirow{3}{*}{$\mathrm{p}^{*}$} \\
\hline & $\mathrm{N}=236(21.2 \%)$ & $N=875(78.8 \%)$ & \\
\hline & \multicolumn{2}{|c|}{ Adherence to guidelines $\mathrm{n}(\%)$} & \\
\hline Number of fruit/vegetables servings/day & $58(24.6)$ & $563(64.3)$ & $\leq 0.001$ \\
\hline Salad/raw vegetables & $101(42.8)$ & $659(75.3)$ & $\leq 0.001$ \\
\hline Cooked vegetables & $37(15.7)$ & $281(32.1)$ & $\leq 0.001$ \\
\hline Fresh fruit & $62(26.3)$ & $515(58.9)$ & $\leq 0.001$ \\
\hline Dairy/dairy products & $162(68.6)$ & $696(79.5)$ & $\leq 0.001$ \\
\hline Cereal/cereal products ${ }^{\mathrm{a}}$ & $102(43.2)$ & $508(58.1)$ & $\leq 0.001$ \\
\hline Snacks & $196(83.1)$ & $780(89.1)$ & 0.012 \\
\hline Fast food/canned food & $175(74.2)$ & $814(93.0)$ & $\leq 0.001$ \\
\hline Lemonade/soft drinks & $141(59.8)$ & $720(82.3)$ & $\leq 0.001$ \\
\hline Meat/sausage products & $33(14.0)$ & $229(26.2)$ & $\leq 0.001$ \\
\hline Fish/seafood & $68(28.8)$ & $367(44.2)$ & $\leq 0.001$ \\
\hline Sweets $^{b}$ & $113(47.9)$ & $465(53.1)$ & ns \\
\hline Cake/cookies & $202(85.6)$ & $740(84.6)$ & ns \\
\hline
\end{tabular}

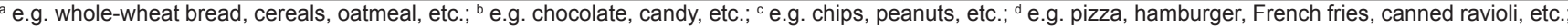

${ }^{*} \mathrm{p}$ values adjusted for BMI and age; ns - not significant

\section{DISCUSSION}

The purpose of the current study was to assess eating habits, dietary guidelines adherence rates, and the associations between importance of eating healthy and dietary guidelines adherence among undergraduate first, second and third year male and female college students in Finland. To the best of our knowledge, such an in depth nutrition and diet inquiry among Finnish university students is a welcome addition to a seemingly thin existing evidence base.

In the current study, we found high levels of dietary adherence ( $>70 \%$ ) for most of the 'unhealthy food' (cake/cookies, snacks, fast food/canned food and lemonade/soft drinks) and moderate adherence for most of the 'healthy food' $(>50 \%)$ (dairy/dairy 
Table 4. Associations between importance of eating healthy and dietary guidelines adherence: by gender

\begin{tabular}{|c|c|c|c|c|c|c|}
\hline & \multicolumn{6}{|c|}{ Importance of eating healthy } \\
\hline & \multicolumn{3}{|c|}{ Men $(\mathrm{N}=323)$} & \multicolumn{3}{|c|}{ Women (N = 781) } \\
\hline & $\begin{array}{c}\text { Not important } \\
\quad \begin{array}{c}N=99 \\
(30.7 \%)\end{array}\end{array}$ & $\begin{array}{c}\text { Important } \\
N=224 \\
(69.4 \%)\end{array}$ & \multirow[t]{2}{*}{$\mathrm{p}^{*}$} & $\begin{array}{l}\text { Not important } \\
\qquad \begin{array}{c}\mathrm{N}=136 \\
(17.4 \%)\end{array}\end{array}$ & $\begin{array}{c}\text { Important } \\
N=645 \\
(82.6 \%)\end{array}$ & \multirow[t]{2}{*}{$\mathbf{p}^{*}$} \\
\hline & \multicolumn{2}{|c|}{ Adherence to guidelines n (\%) } & & \multicolumn{2}{|c|}{ Adherence to guidelines $n(\%)$} & \\
\hline Number of fruit/vegetables daily servings & $18(18.2)$ & $112(50.0)$ & $\leq 0.001$ & $40(29.4)$ & $447(69.3)$ & $\leq 0.001$ \\
\hline Salad/raw vegetables & $36(36.4)$ & $150(67.0)$ & $\leq 0.001$ & $27(19.9)$ & $225(34.9)$ & $\leq 0.001$ \\
\hline Cooked vegetables & $10(10.1)$ & $54(24.1)$ & 0.004 & $90(66.2)$ & $553(85.7)$ & 0.002 \\
\hline Fresh fruit & $14(14.1)$ & $101(45.1)$ & $\leq 0.001$ & $47(34.6)$ & $411(63.7)$ & $\leq 0.001$ \\
\hline Dairy/dairy products & $68(68.7)$ & $181(80.8)$ & 0.021 & $94(69.1)$ & $513(79.5)$ & 0.015 \\
\hline Cereal/cereal products ${ }^{\mathrm{a}}$ & $40(40.4)$ & $101(45.1)$ & ns & $61(44.9)$ & $403(62.5)$ & $\leq 0.001$ \\
\hline Snacks ${ }^{b}$ & $82(82.8)$ & $192(85.7)$ & ns & $113(83.1)$ & $583(90.4)$ & 0.017 \\
\hline Fast food/canned food ${ }^{c}$ & $64(64.7)$ & $190(84.8)$ & $\leq 0.001$ & $110(80.9)$ & $619(96.0)$ & $\leq 0.001$ \\
\hline Lemonade/soft drinks & $50(50.5)$ & $162(72.3)$ & $\leq 0.001$ & $2^{\dagger}(66.7)$ & $223(92.2)$ & $\leq 0.001$ \\
\hline Meat/sausage products & $7(7.1)$ & $32(13.8)$ & ns & $25(18.4)$ & $194(30.1)$ & 0.006 \\
\hline Fish/seafood & $32(32.3)$ & $116(51.8)$ & 0.002 & $36(26.5)$ & $270(41.9)$ & 0.002 \\
\hline Sweets $^{d}$ & $59(59.6)$ & $139(62.1)$ & ns & $54(39.7)$ & $325(50.4)$ & 0.024 \\
\hline Cake/cookies & $90(90.1)$ & $194(86.6)$ & ns & $111(81.6)$ & $542(84.0)$ & ns \\
\hline
\end{tabular}

${ }^{*}$ Chi square test adjusted for BMI and age; ns - not significant; ${ }^{a}$ e.g. whole-wheat bread, cereals, oatmeal, etc.; ${ }^{b} e . g$. chips, peanuts, etc.; ${ }^{\circ}$ e.g. pizza, hamburger, French fries, canned ravioli, etc.; ${ }^{d}$ e.g. chocolate, candy, etc.; ${ }^{\dagger}$ Fisher's exact test used when cell counts were $<5$

products, fruit/vegetables servings/day, fresh fruit, salads/raw vegetables, and cereal/cereal products). Fish/seafood, meat/ sausage products and cooked vegetables showed levels $<50 \%$ for adherence to the guidelines. Women showed better adherence for meat/sausage products, fast food/canned food and for most of the 'healthy food' but not for sweets, lemonade/soft drinks and fish/seafood. Most students considered it important to eat healthy. Importance of eating healthy was significantly associated with adherence for all food groups except for sweets and cake/cookies. These associations remained significant for women but some of them not for men (cereal/cereal products, snacks and sweets).

Our results show an overall high adherence for 'unhealthy food' items and a lower but still high adherence for 'healthy food' items. However, meat/sausage products and fish/seafood products, as well as cooked vegetables had low adherence levels and this might be due to the local cultural/culinary habits that can be often very hard to change. The fast food culture has become rather strongly rooted in Finland, which can be considered one underlying important factor for the general overweight and obesity problem of the population. Based on the results of the most recent university student mail/electronic survey implemented in $2012,41 \%$ of male and $23 \%$ of female students reported a BMI exceeding 25 (i.e. overweight/obese) (27).

When compared to students from other countries, some of our adherence findings (e.g. dairy/dairy products) agree with findings in Spain where there was a high percentage of university students who followed the recommendations of the new Nutritional Pyramid of the Spanish Nutrition Society (SEN) regarding intake of milk and dairy products (13). Conversely, some of our findings contrasted with the Spanish ones. In some instances our Finnish adherence levels were low while the Spanish levels were higher - e.g. meat and fish intake where these two food groups exhibited the lowest adherence amongst the Finns, while in Spain, a high percentage of the students followed the SEN meat and fish intake recommendations (13). Yet in other instances, our Finnish adherence levels were high compared to lower Spanish levels - e.g. fresh fruit, salads/raw vegetables and cereal/cereal products had relatively high adherence amongst the Finns, but not high levels of SEN adherence in Spain for cereals, vegetables, fruits, and legumes (13). In addition, while about $89 \%$ of the Finns adhered to guidelines of fast food/canned food, in Spain, fast food is taken, on average, once a week despite the recommended sporadic monthly intakes (13).

In terms of individual food groups, our cereal/cereal products adherence rate $(54.9 \%)$ was in agreement with undergraduate students in Nigeria where $60 \%$ of the students consumed the recommended minimum number of cereal servings (32). Our number of fruit/vegetables servings/day adherence rate $(55.9 \%)$ compares favourably with Saudi Arabia (only $22 \%$ of students consumed $\geq 5$ servings a day) (33), the USA (only $8.5 \%$ of students reported eating $\geq 5$ servings of fruits and vegetables daily) (18), and Malaysia (only 19\% of university students consumed vegetables more than three times a week) (4). Likewise, our Finnish fresh fruit adherence rate (51.9\%) was favourable compared to the percentages of university students who reported high consumption of fresh fruit (several times a day/daily) in Germany (41.4\%), Denmark (41.7\%), Poland (35.0\%), and Bulgaria (49.6\%) (28). Even in terms of the food groups that exhibited some of the lowest adherence levels across our sample e.g. fish (41.0\%), the Finish adherence level was still higher than the percentages of university students who reported high consumption of fish of at least several times per week (several times a day/daily/several times a week) in Germany (26.6\%), Denmark (34.9\%), Poland (29.2\%), and Bulgaria (38.1\%) (28). Although the adherence rates for several 
food groups were encouraging, the space for betterment of the observed Finnish adherence rates still remains, particularly for the food groups with lower adherence: meat/sausage products adherence (23.6\%) and fish/seafood. This suggested the need for health authorities and educators to work together in order to tailor nutritional education, prevention and intervention programmes targeting these specific food groups.

The observed gender differences are, to an extent, in agreement with a study on young adult Finn men where there was a high consumption of fast food and low consumption of fruit and vegetables. However, in this sample only men were studied (34). Gender differences for the achieved dietary recommendations underline the importance of targeting strategies to improve dietary habits while taking gender into consideration. Our findings also agree with similar gender specific dietary trends observed among Nigerian university students, where more females (42\%) than males $(35 \%)$ achieved the recommendations for meat consumption, consumed adequate quantities of fruits and vegetables (females $40 \%$, males $20 \%$ ), and consumed milk and milk substitutes (females 25\%, males 10\%) (32). In agreement, in Greece, female students had higher scores for healthy eating (35). Nevertheless, in Hong Kong, students' scores on the nutritional habits did not differ significantly by gender (9).

In our study, for most food groups, importance of eating healthy was positively associated with adherence to dietary guidelines. These results seem encouraging for public health, since they suggest that these Finnish students put into action (adherence to guidelines) what they believed as important (eating healthy). The lack of association between importance of eating healthy and adherence to dietary guidelines for sweets and cake/cookies might be due to the fact that often people consume food that feels 'attractive' or 'comforting' while being aware of the possible negative effects. Not many published studies seem to have examined and mobilized the notion of the individual's subjective perception of eating healthy and/or associations with food intake habits. Rather, research has more traditionally focused on e.g. the discipline the student was studying (as proxy for presumed good nutritional knowledge e.g., nutrition students, medical and nursing students), or whether students had sufficient knowledge regarding good dietary habits but failed to apply this knowledge into practice resulting in poor eating habits, although they were generally aware of the negative consequences of such habits (36-38). Future research might address the notion of subjective perception of eating healthy, what it entails, and how it affects individuals' eating habits and food intake.

A related point is the gender differences in the relationships between importance of eating healthy and dietary guidelines adherence, as we found gender differences for sweets and snacks, meat/sausage products and cereal/cereal products. Hence studies of nutritional education, prevention and intervention efforts should note such food groups and gender differences in the planning stage. However, in many of the food items, no gender differences were observed, suggesting also an overall attitude of compliance with recommendations in relation to the importance of eating healthy.

This study has some limitations. The response rate was not very high and this could have affected the results as we are unable to extrapolate any inferences about non-responders. However, students from all disciplines responded and therefore there does not seem to be a preference in responding based on education. Self-reports may be subject to sociability and social desirability and we did not employ objective methods of food consumption measurement. Participants who intentionally or unintentionally distorted their responses may represent a source of bias. We assessed serving sizes only for fruits and vegetables but did not assess serving sizes for the other food groups. We did not conduct test-retest reliability. Given the respondent burden and that it was a general health survey, we did not assess personal determinants such as knowledge, beliefs, perceptions, self-efficacy as well as factors related to social and physical environment that affect eating habits. We examined only one university in Finland and hence generalizations should be cautious. Future research should consider such limitations. Despite these limitations, the current research has much strengths. For data collection, our sample comprised students enrolled from across 7 different faculties and scientific disciplines. Females were overrepresented in the sample than males (a reality at higher education institutions across the globe), hence we analyzed the relationships for the whole sample and by gender to avoid any confounding effects of gender. For the analysis, we used the WHO dietary guidelines that are appropriate for Finland. Recommendations for Nordic countries as well as the recent Baltic sea diet do exist $(39,40)$ but they differ from the WHO recommendations only in terms of food items within food groups (e.g. fruit and vegetables found in Nordic countries are different than the ones recommended by the Mediterranean diet) but not in terms of portions and frequency. Hence we used the WHO dietary guidelines for better comparability with other studies. There were very little missing values in the students' responses (most students answered all the food frequency questions) thus avoiding any potential effects that any missing values could have on the observed estimates of adherence and on the associations that were securitized. We are not aware of any previous studies in Finland on university students' eating habits, diet quality and dietary guidelines adherence that undertook such tasks.

\section{CONCLUSION}

To our knowledge, this could be the first study on dietary habits, guidelines adherence and its association with importance of eating healthy among Finnish university students. The results show a high adherence for 'unhealthy food' groups, moderate adherence for healthier food groups and also accordance between regarding eating healthy as important and actually eating healthy. However, there are still improvements to be considered for specific food groups, especially meat and fish consumption. In addition, gender differences related to adherence to recommendations as well as to the associations between eating healthy and recommendations suggest considering gender as an important factor when implementing public health strategies.

\section{Acknowledgements}

The authors acknowledge the University, the Faculties and students who participated in this study. There was no external financial support/funding for this study. The authors also acknowledge and thank the Student Management Office at the University of Turku for their assistance with the online survey and for their inputs in data collection. 


\section{Conflict of Interests}

None declared

\section{REFERENCES}

1. Deliens T, Clarys P, De Bourdeaudhuij I, Deforche B. Determinants of eating behaviour in university students: a qualitative study using focus group discussions. BMC Public Health. 2014 Jan 18;14:53.

2. AL Qauhiz NM. Obesity among saudi female university students: dietary habits and health behaviors. Egypt Public Health Assoc. 2010;85(1-2):45-59.

3. Abdel-Megeid FY, Abdalharem HM, El-Fetouh AM. Unhealthy nutritional habits in university students are a risk factor for cardiovascular diseases. Saudi Med J. 2011 Jun;32(6):621-7.

4. Gan WY, Mohd NM, Zalilah MS, Hazizi AS. Differences in eating behaviours, dietary intake and body weight status between male and female Malaysian university students. Malays J Nutr. 2011 Aug;17(2):213-28.

5. Drewnowski A, Specter SE. Poverty and obesity: the role of energy density and energy costs. Am J Clin Nutr. 2004 Jan;79(1):6-16.

6. Jessop DC, Herberts C, Solomon L. The impact of financial circumstances on student health. Br J Health Psychol. 2005 Sep;10(Pt 3):421-39.

7. Fabián C, Pagán I, Ríos JL, Betancourt J, Cruz SY, González AM, et al. Dietary patterns and their association with sociodemographic characteristics and perceived academic stress of college students in Puerto Rico. P R Health Sci J. 2013 Mar;32(1):36-43.

8. Freedman MR. Development, evaluation, and validation of environmental assessment tools to evaluate the college nutrition environment. J Am Coll Health. 2010 May-Jun;58(6):565-8.

9. Lee RL, Loke AJ. Health-promoting behaviors and psychosocial wellbeing of university students in Hong Kong. Public Health Nurs. 2005 May-Jun;22(3):209-20.

10. Kremmyda LS, Papadaki A, Hondros G, Kapsokefalou M, Scott JA. Differentiating between the effect of rapid dietary acculturation and the effect of living away from home for the first time, on the diets of Greek students studying in Glasgow. Appetite. 2008 Mar-May;50(2-3):455-63.

11. Vilela S, Santos S, Padrão P, Caraher M. Length of migration and eating habits of Portuguese university students living in London, United kingdom. Ecol Food Nutr. 2014;53(4):419-35.

12. Aboul Azm S, Elebiary HA. Prevalence of overweight and obesity in relation to life-style among Saudi Arabian female nursing students. Med J Cairo Univ. 2010 Jun;78(1):377-85.

13. Bayona-Marzo I, Navas-Cámara FJ, Fernández de Santiago FJ, MingoGómez T, de la Fuente-Sanz MA, Cacho del Amo A. Eating habits in physical therapy students. Nutr Hosp. 2007 Sep-Oct;22(5):573-7. (In Spanish.)

14. Egeda Manzanera JM, Rodrigo Vega M. Adherence to the mediterranean diet of future teachers. Nutr Hosp. 2014 Aug 1;30(2):343-50. (In Spanish.)

15. Míguez Bernárdez M, Castro Sobrino L, Collins Greene A, de la Montaña Miguélez J. Variations of the diet of Galician university students (Ourense Campus) in relation to the pattern of the cardioprotective Mediterranean diet. Nutr Hosp. 2013 Nov 1;28(6):2099-106. (In Spanish.)

16. Włodarek D, Głabska D, Lange E. The effect of dairy products choice on calcium dietary intake in female university students of nutritional faculty. Rocz Panstw Zakl Hig. 2014;65(1):35-9.

17. Rodríguez F, Palma X, Romo A, Escobar D, Aragú B, Espinoza L, et al. Eating habits, physical activity and socioeconomic level in university students of Chile. Nutr Hosp. 2013 Mar-Apr;28(2):447-55. (In Spanish.)

18. American College Health Association. American College Health Association-National College Health Assessment Spring 2008 Reference Group Data Report (abridged): the American College Health Association. J Am Coll Health. 2009 Mar-Apr;57(5):477-88.

19. Kresić G, Kendel Jovanović G, Pavicić Zezel S, Cvijanović O, Ivezić G. The effect of nutrition knowledge on dietary intake among Croatian university students. Coll Antropol. 2009 Dec;33(4):1047-56.

20. Van Diepen S, Scholten AM, Korobili C, Kyrli D, Tsigga M, Van Dieijen $\mathrm{T}$, et al. Greater Mediterranean diet adherence is observed in Dutch compared with Greek university students. Nutr Metab Cardiovasc Dis. $2011 \mathrm{Jul} ; 21(7): 534-40$
21. Roos E, Talala K, Laaksonen M, Helakorpi S, Rahkonen O, Uutela A, et al. Trends of socioeconomic differences in daily vegetable consumption, 1979-2002. Eur J Clin Nutr. 2008 Jul;62(7):823-33.

22. Pohjanheimo T, Luomala H, Tahvonen R. Finnish adolescents' attitudes towards wholegrain bread and healthiness. J Sci Food Agric. 2010 Jul;90(9):1538-44

23. Laitinen P, Nissinen A, Myllykangas M. Fat consumption of first-grade students in elementary school. Quality and quantity of fats used at home and at school. Hoitotiede. 1993;5(2):50-5. (In Finnish.)

24. Prättälä R, Helasoja V, Mykkänen $H$. The consumption of rye bread and white bread as dimensions of health lifestyles in Finland. Public Health Nutr. 2001 Jun;4(3):813-9.

25. Heikkinen R, Kivastik J, Kingisepp PH, Hirvonen L, Näyhä S. Smoking differences between university faculties in Tartu, Estonia, and Oulu, Finland, after the disruption of communism. Soz Praventivmed. 2006;51(6):381-91.

26. Kuuppelomäki M, Utriainen P. A 3 year follow-up study of health care students' sense of coherence and related smoking, drinking and physical exercise factors. Int J Nurs Stud. 2003 May;40(4):383-8.

27. Kunttu K, Pesonen T. Health survey of university students 2012 . Helsinki: Ylioppilaiden terveydenhoitosäätiön tutkimuksia 47; 2013. (In Finnish.)

28. El Ansari W, Stock C, Mikolajczyk RT. Relationships between food consumption and living arrangements among university students in four European countries - a cross-sectional study. Nutr J. 2012 Apr 24;11:28.

29. Osler M, Heitmann BL. The validity of a short food frequency questionnaire and its ability to measure changes in food intake: a longitudinal study. Int J Epidemiol. 1996 Oct;25(5):1023-9.

30. Roddam AW, Spencer E, Banks E, Beral V, Reeves G, Appleby P, et al. Reproducibility of a short semi-quantitative food group questionnaire and its performance in estimating nutrient intake compared with a 7-day diet diary in the Million Women Study. Public Health Nutr. 2005 Apr;8(2):20113.

31. World Health Organization. CINDI dietary guide. Copenhagen: WHO Regional Office for Europe; 2000

32. Otemuyiwa IO, Adewusi SR. Food choice and meal consumption pattern among undergraduate students in two universities in Southwestern Nigeria. Nutr Health. 2012 Oct;21(4):233-45.

33. Al-Otaibi HH. The pattern of fruit and vegetable consumption among Saudi university students. Glob J Health Sci. 2013 Dec 24;6(2):155-62.

34. Bingham CM, Jallinoja P, Lahti-Koski M, Absetz P, Paturi M, Pihlajamäki H, et al. Quality of diet and food choices of Finnish young men: a sociodemographic and health behavior approach. Public Health Nutr. 2010 Jun;13(6A):980-6.

35. Tirodimos I, Georgouvia I, Savvala TN, Karanika E, Noukari D. Healthy lifestyle habits among Greek university students: differences by sex and faculty of study. East Mediterr Health J. 2009 May-Jun;15(3):722-8.

36. Sajwani RA1, Shoukat S, Raza R, Shiekh MM, Rashid Q, Siddique MS, et al. Knowledge and practice of healthy lifestyle and dietary habits in medical and non-medical students of Karachi, Pakistan. J Pak Med Assoc. 2009 Sep;59(9):650-5.

37. Sakamaki R, Toyama K, Amamoto R, Liu CJ, Shinfuku N: Nutritional knowledge, food habits and health attitude of Chinese university students: a cross sectional study. Nutr J. 2005 Feb 9;4:4

38. Matvienko O, Lewis DS, Schafer E. A college nutrition science course as an intervention to prevent weight gain in female college freshmen. J Nutr Educ. 2001 Mar-Apr;33(2):95-101.

39. Kanerva N, Kaartinen NE, Schwab U, Lahti-Koski M, Männistö S. Adherence to the Baltic Sea diet consumed in the Nordic countries is associated with lower abdominal obesity. Br J Nutr. 2013 Feb 14;109(3):520-8.

40. Uusitupa M, Hermansen K, Savolainen MJ, Schwab U, Kolehmainen M, Brader L, et al. Effects of an isocaloric healthy Nordic diet on insulin sensitivity, lipid profile and inflammation markers in metabolic syndrome - a randomized study (SYSDIET). J Intern Med. 2013 Jul;274(1):52-66.

Received November 19, 2014 Accepted in revised form July 3, 2015 